\title{
A RELEVÂNCIA DA DECISÃO DO SUPREMO TRIBUNAL FEDERAL SOBRE A INCONSTITUCIONALIDADE DO ART. 1.790 CC NO PLANEJAMENTO SUCESSÓRIO
}

Daniele Chaves Teixeira*

\begin{abstract}
Sumário: 1 . Notas introdutórias - 2. O direito sucessório na sociedade contemporânea e a desconstrução dos seus pilares: família e propriedade - 3. A necessidade do planejamento sucessório frente à rigidez do direito das sucessões no Brasil - 4. Importância da decisão da inconstitucionalidade do art. 1.790 CC pelo STF nos pressupostos do planejamento sucessório - Considerações finais Referências.
\end{abstract}

\section{NOTAS INTRODUTÓRIAS}

O artigo pretende destacar a importância da decisão do Supremo Tribunal Federal sobre a inconstitucionalidade do art. 1.790 do Código Civil brasileiro nos pressupostos do planejamento sucessório. Primeiramente, se analisará o porquê da relevância do planejamento sucessório na atualidade jurídica do Brasil, derivado do descompasso que ocorre entre a sociedade contemporânea e o direito das sucessões. O estudo demonstrará quais são os fatores que levaram ao crescimento do interesse pelo direito sucessório e de que forma as consequências das transformações da sociedade atingem os alicerces do direito das sucessões: a propriedade e a família. Deixará claro, também, que a falta de liberdade do ordenamento provoca uma demanda pelo planejamento sucessório.

\footnotetext{
Doutora e Mestre em Direito Civil pela Universidade do Estado do Rio de Janeiro (UERJ); Especialista em Direito Civil pela Universidade de Camerino, Itália; Especialista em Direito Privado pela PUC-RJ; Advogada.
} 
Com efeito, deve-se analisar o que é um planejamento sucessório e com que finalidade deve ser realizado. Primeiramente, o planejamento sucessório é um instrumento jurídico que permite a adoção de uma estratégia voltada para a transferência eficaz e eficiente do patrimônio de uma pessoa após a sua morte. ${ }^{1}$ Vale ressaltar, ainda, que o planejamento é realizado em vida e que sua completa aplicabilidade de efeitos ocorrerá após a morte. Ele é essencial para aquele que quer que sua vontade prevaleça após sua morte, e isso pode ser realizado por meio de diversos instrumentos jurídicos: o testamento é somente um deles.

As características da sociedade brasileira atual exigem uma melhor estruturação patrimonial para o pós-morte. Um adequado planejamento democratizaria e internalizaria a vontade do autor da herança. ${ }^{2} \mathrm{O}$ planejamento sucessório atende à procura por organização e permite que as pessoas enfrentem a dificuldade humana de lidar com a morte. A procura crescente por maiores informaçôes na questão sucessória em relação ao patrimônio e à família é questão fática na atualidade. Pode-se entender que o planejamento sucessório é a maior consequência do fenômeno da pluralidade familiar na sociedade. ${ }^{3}$

É de vital importância para um planejamento sucessório que em seus pressupostos se analisem três pontos: a) qualificar a pessoa; b) levantar o ativo e o passivo do patrimônio; e c) verificar a vontade do autor da herança. A decisão do Supremo Tribunal Federal sobre a inconstitucionalidade do art. 1.790 do Código Civil reflete diretamente na qualificação da pessoa que irá fazer o planejamento sucessório, pois nesse momento deve-se verificar se o companheiro é ou não herdeiro necessário. Cabe ressaltar, que definir a questão é essencial para um planejamento sucessório, seus efeitos e para segurança jurídica.

\section{O DIREITO SUCESSÓRIO NA SOCIEDADE CONTEMPORÂNEA E A DESCONSTRUÇÃO DOS SEUS PILARES: FAMÍLIA E PROPRIEDADE}

O Direito Sucessório trata de uma questão muito delicada para as pessoas, que é, exatamente, encarar a finitude humana: a própria morte. A função do Direito das

1 OLIVEIRA, Euclides de. Planejamento sucessório: regime de bens e seu reflexo na transmissão da herança. Federação das Indústrias do Estado de São Paulo - FIESP. Disponível em: <http://www.fiesp.com.br/irs/conjur/pdf/transparencias_reuniao_conjur_25_10_10_-_euclides_benedito_de_oliveira_planej_sucess_palest_conjur.pdf>. Acesso em: 14 jul. 2011.

2 OLIVA, Milena Donato. Do negócio fiduciário à fidúcia. São Paulo: Atlas, 2014, p. 118.

3 HIRONAKA, Giselda Maria Fernandes Novaes. Planejar é preciso: planejamento sucessório para as novas famílias. Entrevista. Revista IBDFAM. Belo Horizonte: Instituto Brasileiro de Direito de Família, 10 ed., abr. 2014, p. 6. 
Sucessões é estabelecer o destino das situações jurídicas transmissíveis do autor da herança, conforme os ditames constitucionais. ${ }^{4}$ Com a morte, ocorre a abertura da sucessão, e é apenas nesse momento que nascem os direitos hereditários.

O vigente Código Civil brasileiro, na parte do livro do Direito das Sucessões, pouco avançou. Ainda reflete institutos que não se coadunam com a sociedade contemporânea, com todas as complexidades sociais, porque, em geral, o sistema atual das sucessões "não atende aos anseios finais dos indivíduos, detenham eles vastos patrimônios ou não". 5 O Código Civil de 2002, no que concerne ao Direito Sucessório, ainda se baseia em um modelo de família que não corresponde ao perfil das famílias da atual sociedade brasileira.

Os fatores principais que provocam essas reavaliações do direito das sucessões decorrem de transformaçôes das famílias e dos bens, ou seja, são oriundas de questôes sociais e econômicas. ${ }^{6}$ Consequentemente, as necessidades de maior atenção ao direito sucessório - e, principalmente, ao crescimento e à importância dessa área - são destacadas por Walter Pintens. Segundo o doutrinador, no passado, o impacto do direito sucessório, especialmente o direito sucessório internacional, era bastante limitado, uma vez que os ganhos eram modestos, a real riqueza era para poucos e a posse de propriedades em países estrangeiros era raro.

O autor destaca, ainda, que, durante as próximas décadas, a transmissão de riqueza pela herança será muito importante para toda a Europa, pois os Estados cresceram. Vale ressaltar que não é incomum que o capital seja investido transnacionalmente, porque um número cada vez maior de pessoas têm adquirido propriedades no exterior ou contas bancárias em países estrangeiros, levando ao crescimento dos casos de sucessão transfronteiriça. ${ }^{8}$

4 NEVARES, Ana Luiza Maia. A função promocional do testamento: tendências do direito sucessório. Rio de Janeiro: Renovar, 2009, p. 8.

5 GAYA, Karyna Saraiva Leão. Planejamento sucessório: uma saudável preocupação com o futuro. Revista Sintese: Direito de Família. Porto Alegre: Síntese, ano XIII, n. 70, fev./mar. 2012, p. 124.

6 REALE, Miguel. Liçôes preliminares de direito. 25. ed. São Paulo: Saraiva, 2000, p. 19-21.

7 PINTENS, Walter. Need and opportunity of convergence in European succession laws. In: ANDERSON, Mirian; ARROYO I AMAYUELAS, Esther (Ed.). The law of succession: testamentary freedom. European perspectives. Amsterdam: European Studies in Private Law, 2011, p. 5.

8 PINTENS, Walter. Need and opportunity of convergence in European succession laws. In: ANDERSON, Mirian; ARROYO I AMAYUELAS, Esther (Ed.). The law of succession: testamentary freedom. European perspectives. Amsterdam: European Studies in Private Law, 2011, p. 6. 
Essa expansão é característica do mundo globalizado, tecnológico, imediatista, consumista e fluido em que vive a sociedade contemporânea' ${ }^{9}$ É necessário fazer algumas consideraçôes sobre o mundo atual, com base na seguinte pergunta: o que é a globalização? Ela, normalmente, é associada a processos econômicos, tais como a circulação de bens e capitais, as ampliações dos mercados, ou, ainda, a integração produtiva em escala mundial. ${ }^{10}$

Entre as principais transformações decorrentes da globalização, encontram-se a organização econômica; as relações sociais; os padrōes de vida e a cultura; o Estado e a política. Constatam-se, também, outros aspectos, tais como: as migrações e as viagens internacionais, como também o aumento dos contatos e das redes de comunicações; o crescimento de relações e organizações interestatais; o aumento de redes de organizações não governamentais; a difusão de novas tecnologias; a internacionalização do conhecimento social e as novas formas de interdependência mundial. ${ }^{11}$

Deve-se dar destaque para a questão do desenvolvimento tecnológico e, consequentemente, para a velocidade com que surgem novas técnicas de comunicação eletrônica. Toda essa tecnologia levou à unificação de espaços, ou seja, à intercomunicação dos lugares, que se tornaram próximos. Assim também é o caso de empresas multinacionais que se transformaram em transnacionais. Hoje não há mais matrizes situadas em um território nacional, controlando subsidiárias estrangeiras. Isso se deve ao fato de a globalização ter possibilitado a mobilidade e a descentralização. Dessa forma, uma empresa global opera em escala planetária. ${ }^{12}$

Pode-se dizer que nas últimas décadas, principalmente pela influência do desenvolvimento da comunicação eletrônica global instantânea, as circunstâncias se alteraram de forma radical. É um mundo no qual ninguém é mais forasteiro; em que as tradiçôes preexistentes não podem evitar o contato com outros modos de vidas diferentes. ${ }^{13}$ Assim, Boaventura de Souza Santos afirma que "hoje as identidades culturais não são rígidas nem, muito menos, imutáveis. São resultados sempre transitórios e fugazes de processos de identificação." ${ }^{14}$

9 TEIXEIRA, Daniele. Planejamento Sucessório: pressupostos e limites. 2. reimpr. Belo Horizonte: Fórum, 2018, p. 26

10 VIEIRA, Liszt. Cidadania e globalização. 5. ed. Rio de Janeiro: Record, 2001, p. 72.

11 Ibid, p. 74.

12 VIEIRA, Liszt. Cidadania e globalização. 5. ed. Rio de Janeiro: Record, 2001, p. 98.

13 GIDDENS, Anthony. A vida em uma sociedade pós-tradicional. In: GIDDENS, Anthony; LASH, Scott; BECK, Ulrich (Org.). Modernização reflexiva: política, tradição, estética na ordem social moderna. 2. ed. Tradução de Magda Lopes. São Paulo: Unesp, 2012, p. 150.

14 SANTOS, Boaventura de Sousa. Pela mão de Alice: o social e o político na pós-modernidade. 8. ed. São Paulo: Cortez, 2001, p. 135. 
Zygmunt Bauman também retrata precisamente essa sociedade instantânea e fluida. ${ }^{15} \mathrm{O}$ autor considera que "o derretimento dos sólidos levou à progressiva libertação da economia de seus tradicionais embaraços políticos, éticos e culturais. Sedimentou uma nova ordem, definida, principalmente, em temos econômicos". ${ }^{16}$ Seria imprudente negar a mudança que a "modernidade fluida" produziu na condição humana, alterando, dessa forma, a condição política-vida de um modo radical e, consequentemente, ampliando a necessidade de se repensar os velhos conceitos.

Outra característica da sociedade atual é o consumismo. Nesse caso, deve-se retornar a Bauman, para quem a vida líquida, assim como a sociedade liquido-moderna, não pode permanecer em seu curso por muito tempo, ou seja, a vida líquida é uma vida precária, vivida em condições de incerteza constante. ${ }^{17}$

Embora seja relevante a perspectiva exposta a respeito da sociedade líquida, globalizada, conectada, que vivencia os efeitos dessas transformações socioeconômicas, vale destacar que esses fatores servem para contextualizar a sociedade contemporânea, demonstrar o descompasso com o Direito Sucessório Brasileiro e ressaltar a necessidade de adequar o direito das sucessões a essa nova sociedade.

O direito das sucessóes - entendido como parte do direito civil no qual a estrutura da sociedade se reflete - não pode desconhecer as particularidades e as exigências dessa sociedade, sob pena de não atingir o fim a que se propóe. ${ }^{18} \mathrm{Com}$ o evoluir das condições sociais, o direito deve também evoluir, o que normalmente acontece. Entretanto, existem áreas do mundo jurídico mais sensíveis a essas transformaçốes, caso em que se inclui o direito das sucessóes.

15 Em sua obra Modernidade líquida, ele denomina como "'fluidez' a principal metáfora para o estágio presente da era moderna". Segundo ele, os fluidos não fixam o espaço, nem prendem o tempo; já para os sólidos, o que conta é o tempo mais do que o espaço que ocupa [...] As "descrições de líquidos são fotos instantâneas, que precisam ser datadas [...] A extraordinária mobilidade dos fluidos é o que os associa à ideia de "leveza" [...] Por isso, "fluidez" ou "liquidez" são metáforas adequadas quando se quer capturar "a natureza da presente fase, nova de muitas maneiras, na história da modernidade.” Cf. BAUMAN, Zygmunt. Modernidade líquida. Tradução de Plínio Dentzien. Rio de Janeiro: Jorge Zahar, 2001, p. 8-9.

16 BAUMAN, Zygmunt. Modernidade líquida. Tradução de Plínio Dentzien. Rio de Janeiro: Jorge Zahar, 2001 p. 10.

17 BAUMAN, Zygmunt. Vida líquida. Tradução de Carlos Alberto Medeiros. Rio de Janeiro: Jorge Zahar, 2007, p. 7-8.

18 GALVAO TELLES, Inocêncio. Apontamentos para a história do direito das sucessões português. Separata da Revista da Faculdade de Direito da Universidade de Lisboa. Lisboa, v. XV, Lisboa, 1963, p. 6. 
Vale destacar que o direito sucessório foi necessário para fortalecer o poder econômico do cidadão e tornou-se, ao lado da propriedade, a base da expansão do comércio e dos negócios econômicos.

Dessa maneira, faz-se necessária a análise das relações familiares, diante da conexão jurídica e social do direito de família com o direito de sucessões, somada à transformação enfrentada pela família com o reconhecimento jurídico de alguns novos modelos familiares. Consequentemente, ocorre uma alteração substancial no direito sucessório em sua concepção da titularidade e da posse do patrimônio e no destino destes após a morte. ${ }^{19}$

$\mathrm{Na}$ verdade, nos últimos decênios, a família transformou-se, passando a corresponder a muitas das aspiraçóes individuais presentes no mundo ocidental. Isso porque "quase quarenta anos depois do movimento cultural de jovens que a consideravam a principal fonte de repressão e de conformismo social, a família tem sido vista como um espaço privilegiado de solidariedade e de realização pessoal". ${ }^{20}$

É possível perceber que essas transformações das famílias ocorreram em vários ordenamentos e que, consequentemente, exigiram várias reformas legislativas no direito sucessório, na União Europeia. Os principais fatores para que essas mudanças ocorressem foram: a industrialização; a urbanização; a redução da dimensão da família; o processo de mobilidade social; e a incorporação da mulher ao mercado de trabalho. ${ }^{21}$

Atualmente a família é reivindicada como o único valor seguro ao qual ninguém quer renunciar. Ela é amada, sonhada e desejada por homens, mulheres e crianças de todas as idades, de todas as orientações sexuais e de todas as condiçōes. ${ }^{22}$

Com o advento da CRFB/1988, ocorreram grandes alteraçôes na família, com o tripé constitucional que inseriu a pluralidade das entidades familiares, como também a igualdade entre os cônjuges e entre os filhos. Transformaram-se, dessa

19 REBOLLEDO VARELA, Ángel Luis. La actualización del derecho sucesorio espanôl ante los cambios sociológicos y jurídicos de la familia: conclusiones de una investigación. In: REBOLLEDO VARELA, Ángel Luis (Coord.). La familia en el derecho de sucesiones: cuestiones actuales y perspectivas de futuro. Madrid: Dykinson, 2010, p. 23.

20 MORAES, Maria Celina Bodin de. A família democrática. In: MORAES, Maria Celina Bodin de. Na medida da pessoa humana. Rio de Janeiro: Renovar, 2010, p. 208.

21 FACAL FONDO, Teresa; TORRÉNS CALLE, Ma Del Pilar. Cambios sociológicos en la familia con repercusión en el derecho de sucesiones. In: REBOLLEDO VARELA, Ángel Luis (Coord.). La familia en el derecho de sucesiones: cuestiones actuales y perspectivas de futuro. Madrid: Dykinson, 2010, p. 43-52.

22 ROUDINESCO, Elizabeth. A família em desordem. Tradução de André Telles. Rio de Janeiro: Jorge Zahar, 2003, p. 198. 
maneira, as relações familiares, pois a família deixou de ser algo institucional - ter a instituição como fim -, para ser a família instrumental, ou seja, o meio para realizar o desenvolvimento dos filhos e promover a dignidade de seus integrantes. ${ }^{23}$

Para além das várias exigências de adequação impostas ao regime sucessório, destacam-se, ainda, fatores inerentes aos próprios bens: natureza, função e fluidez. ${ }^{24}$ Isso se deve, em boa parte, ao desenvolvimento tecnológico e científico, visto que "surgem a cada dia novos bens, deixando outros simplesmente de existir". ${ }^{25}$

No regime atual do Código Civil Brasileiro, ${ }^{26}$ as classificações dos bens decorrem de três critérios fundamentais: a) de suas características naturais (individualidade); b) de suas recíprocas relações quando considerados entre si (uns em relação aos outros); c) de sua titularidade. ${ }^{27}$ Por isso, destaque-se a necessidade de se observar a disciplina dos bens jurídicos, pois o Código Civil Brasileiro os delineia de forma tipificadora e abstrata, difundida em seu aspecto estrutural, "a desenhar classificação aparentemente neutra de objetos sujeitos ao tráfego jurídico, adquire

23 TEPEDINO, Gustavo. A disciplina civil-constitucional das relações familiares. In: TEPEDINO, Gustavo. Temas de direito civil. 3. ed. rev. atual. Rio de Janeiro: Renovar, 2004, p. 398.

24 "Coisa constitui-se em gênero, que abrange todos os elementos perceptíveis, sendo bem a espécie, a traduzir aquilo que pode se constituir em objeto de direito, e que pode ser considerado coisa em sentido jurídico”. Cf. TEPEDINO, Gustavo. Regime jurídico dos bens no Código Civil. In: Venosa, Sílvio de Salvo; Gagliardi, Rafael Villar; Nasser, Paulo Magalhães (Coord.). 10 anos do Código Civil: desafios e perspectivas. São Paulo: Atlas, 2012, p. 48.

25 "Elementos da natureza, como o ar, o oceano, as camadas de águas profundas conhecidas como pré-sal; os rios, os animais selvagens, antes considerados como inaptos a despertar interesse jurídico, tornam-se a cada dia mais indispensáveis à humanidade, sendo igualmente objeto de direito as diversas formas de energia, como a eletricidade, o gás, o vapor”. TEPEDINO, Gustavo. Regime jurídico dos bens no Código Civil. In: Venosa, Sílvio de Salvo; Gagliardi, Rafael Villar; Nasser, Paulo Magalhães (Coord.). 10 anos do Código Civil: desafios e perspectivas. São Paulo: Atlas, 2012, p. 50

26 "O CC1916 não diferenciou coisas e bens. O CC unifica a linguagem, referindo-se a bens, de modo a abranger os objetos materiais e os imateriais". TEPEDINO, Gustavo; BARBOZA; Heloisa Helena; MORAES, Maria Celina Bodin de. Código Civil interpretado conforme a Constituição da República I. Rio de Janeiro: Renovar, 2004, p. 171.

27 Na primeira classificação está no Livro II, Título único, Capítulo I do Código Civil de 2002, denominado "Dos Bens considerados em si mesmos", com as distinções entre bens imóveis e móveis (arts. 79 a 84); fungíveis e não fungíveis (art. 85); consumíveis e não consumíveis (art. 86); divisíveis e indivisíveis (arts. 87 e 88); singulares e coletivos (arts 89 a 91). A segunda classificação está no Livro II, Capítulo II, intitulado "Dos Bens reciprocamente considerados" que regula os principais e acessórios (art. 92), as pertenças (arts. 93 e 94), os frutos e produtos (art. 95), e as benfeitorias (arts. 96 e 97). A terceira classificação está, também, no mesmo Livro II, Capítulo III, nomeado aos "Bens Públicos", que disciplina os bens que integram a titularidade do Poder Público (arts. 98 a 102). 
renovada dimensão e importância no Direito contemporâneo. Para tanto, há que se deslocar a análise para a perspectiva funcional" 28 - ou seja, deve-se destacar o papel que o bem jurídico representa no exercício das liberdades fundamentais, da autonomia privada e do controle de riquezas. ${ }^{29}$

Segundo Gustavo Tepedino "o bem jurídico pode representar coisas imateriais, incorpóreas ou intangíveis, a exemplo dos direitos autorais, da clientela, da marca, da informação, dentre outras". ${ }^{30}$ Dessa forma, é preciso redimensionar a noção de bens, de relativa e mutável, para conformá-la ao contexto socioeconômico, ${ }^{31}$ pois eles "compõem o patrimônio dos sujeitos e consistem em objeto de aproveitamento econômico, a demandarem tutela por parte do ordenamento jurídico". ${ }^{32}$

28 Ainda o autor: "de tal modo que a qualificação do bem jurídico se encontre sempre associada à sua função, investigando-se, na dinâmica da relação jurídica em que se insere, a destinação do bem de acordo com os interesses tutelados" TEPEDINO, Gustavo. Regime jurídico dos bens no Código Civil. In: Venosa, Sílvio de Salvo; Gagliardi, Rafael Villar; Nasser, Paulo Magalhães (Coord.). 10 anos do Código Civil: desafios e perspectivas. São Paulo: Atlas, 2012, p. 78.

29 TEPEDINO, Gustavo. Regime jurídico dos bens no Código Civil. In: Venosa, Sílvio de Salvo; Gagliardi, Rafael Villar; Nasser, Paulo Magalhães (Coord.). 10 anos do Código Civil: desafios e perspectivas. São Paulo: Atlas, 2012, p. 78.

30 TEPEDINO, Gustavo. Livro (eletrônico) e o perfil funcional na experiência brasileira. In: VICENTE, Dário Moreira; VIEIRA, José Alberto Coelho; CASIMIRO, Sofia de Vasconcelos; SILVA, Ana Maria Pereira da (Org.). Estudos de direito intelectual em homenagem ao Prof. Doutor José de Oliveira Ascensão. 1. ed. Coimbra: Almedina, 2015, p. 270.

31 "O conceito de bem é histórico e relativo. Histórico, porque a ideia de utilidade tem variado de acordo com as diversas épocas da cultura humana, e relativo porque tal variação se verifica em face das necessidades diversas por que o homem tem passado. Nos primórdios, as necessidades eram puramente vitais, respeitantes à defesa e à sobrevivência do indivíduo e do grupo. As coisas úteis e apropriáveis diziam respeito à vida orgânica e material dos indivíduos. Com a evolução da espécie humana e o desenvolvimento da vida espiritual, expresso na arte, na ciência, na religião, na cultura, enfim, surgiram novas exigências e novas utilidades, passando a noção de bem a ter sentido diverso do que tinha primitivamente". Cf. AMARAL, Francisco. Direito civil: introdução. 6. ed. ver. atual. e aum.. Rio de Janeiro: Renovar, 2006, p. 309.

32 "De fato, a partir do exercício da titularidade sobre os bens, corpóreos ou incorpóreos, os sujeitos extraem as utilidades econômicas pretendidas, de sorte que as normas que irão reger o aproveitamento econômico dos bens serão determinadas de acordo com a finalidade e função que tais bens desempenham". Cf. TEPEDINO, Gustavo. Livro (eletrônico) e o perfil funcional na experiência brasileira. In: VICENTE, Dário Moreira; VIEIRA, José Alberto Coelho; CASIMIRO, Sofia de Vasconcelos; SILVA, Ana Maria Pereira da (Org.). Estudos de direito intelectual em homenagem ao Prof. Doutor José de Oliveira Ascensão. 1. ed. Coimbra: Almedina, 2015, p. 272. 
Percebe-se, assim, que os bens de valor hoje existem de várias formas, detentores de maior fluidez no tráfego negocial. ${ }^{33}$ Além disso, também se faz necessário lembrar que houve valorização econômica e financeira desses bens, fato que tem direta e indeclinável repercussão na transmissão por força de sucessão, especialmente mortis causa.

Conclui-se, dessa forma, que as riquezas não mais se encontram apenas nas propriedades, ou nos bens imóveis. Pelo contrário, com as transformações e fatores acima destacados verifica-se que é possível ter um patrimônio representativo em bens móveis, que possuem uma circulação mais ágil e menos formal. Da mesma forma, assim como a propriedade, a família também é outra, como se viu nos parágrafos anteriores. Não existe mais um único modelo de família legal, e sim várias formas de entidades familiares.

\section{A NECESSIDADE DO PLANEJAMENTO SUCESSÓRIO FRENTE À RIGIDEZ DO DIREITO DAS SUCESSÕES NO BRASIL}

Podemos destacar a importância que o direito sucessório adquiriu nas últimas décadas em função de questôes socioeconômicas, principalmente como consequência das transformações nos institutos da família e da propriedade, que constituem os pilares do direito das sucessões. Em virtude desses mesmos fatores, vários ordenamentos europeus sofreram alterações no direito sucessório. Faz-se igualmente necessário rever os institutos de uma forma funcional dessa área do direito civil brasileiro.

O direito sucessório brasileiro está extremamente engessado, muito distante das necessidades das famílias contemporâneas e das funções patrimoniais, que devem ser atendidas à luz dos princípios constitucionais, mas que dispõem de poucas alternativas para exercer a própria autonomia ${ }^{34}$. Por isso o planejamento sucessório é tão necessário na atualidade. Com base na liberdade de testar, é possível buscar

33 "No cenário contemporâneo, em que se avolumam transações cada vez mais aceleradas, intensifica-se a necessidade de fortalecer o mercado de crédito, desiderato apenas alcançável por meio do desenvolvimento de mecanismos capazes de garantir aos credores a rápida e eficaz recuperação do crédito”. Cf. GUEDES, Gisela Sampaio da Cruz; TERRA, Aline de Miranda Valverde. Alienação fiduciária em garantia de bens imóveis: possíveis soluçôes para as deficiências e insuficiências da disciplina legal. Civilistica.com. Rio de Janeiro, a. 4, n. 1, 2015. Disponível em: <http://civilistica.com/alienacao-fiduciaria-em-garantia-de-bens-imoveis/>. Acesso em: 6 jan. 2016.

34 TEIXEIRA, Daniele. Planejamento Sucessório: pressupostos e limites. 2. reimpr. Belo Horizonte: Fórum, 2018, p. 56. 
instrumentos para a efetivação desejada e corrigir algumas distorções que o sistema jurídico provoca.

No entanto, o planejamento sucessório enfrenta algumas dificuldades para sua efetivação, cujas principais são: a) a demanda por uma maior autonomia do autor da herança perante os limites de nosso sistema sucessório; e b) a questão legislativa e a problematização de leis no tempo ${ }^{35}$.

O primeiro problema decorre exatamente da procura da sociedade por maior autonomia ao dispor de seu patrimônio, em contraposição à rigidez do sistema sucessório brasileiro, expresso nas disposiçōes de limite da legítima, na proibição dos pactos sucessórios, nas limitações às doações, nos regimes de bens e seus respectivos efeitos no ordenamento jurídico. Com o Código Civil de 2002, agravou-se a situação de pouca liberdade com a inserção do cônjuge como herdeiro necessário.

Entretanto, a análise da questão por maior ou menor liberdade deve ser sempre realizada com base nos direitos e garantias fundamentais expressos na $\mathrm{CRFB} / 1988$. Na Constituição, não só estão presentes direitos à propriedade privada, à livre iniciativa e à herança, como também, princípios da solidariedade, da proteção familiar e, principalmente, da funcionalização dos institutos do direito civil.

Outra dificuldade decorre do fato de o planejamento sucessório ser realizado em um momento atual para vir a ser cumprido, na completude de seus efeitos, somente após a morte do indivíduo. O planejamento está, portanto, sujeito a possíveis alteraçōes supervenientes na legislação brasileira. Ou seja, "eventuais alterações legislativas impõem uma reavaliação do planejamento sucessório e a readequação às condiçôes pessoais do titular e aos objetivos traçados". ${ }^{36}$ Como exemplo dos efeitos supervenientes da alteração legislativa para o planejamento sucessório, há a significativa alteração do instituto da colação com o ingresso no ordenamento do Código de Processo Civil Brasileiro, fator de significativa importância para um planejamento sucessório.

Conforme já assinalado, a relevância do planejamento sucessório e sua respectiva demanda são crescentes nos dias de hoje, em razão de diversos motivos. Entre eles, estão: as transformações das famílias e seus desdobramentos jurídicos;

35 TEIXEIRA, Daniele. Planejamento Sucessório: pressupostos e limites. 2. reimpr. Belo Horizonte: Fórum, 2018, p. 59.

36 CRUZ, Elisa; AZEVEDO, Lilibeth. Planejamento sucessório. In: TEPEDINO, Gustavo; FACHIN, Luiz Edson (Org.). Diálogos sobre direito civil, vol. III. Rio de Janeiro: Renovar, 2012, p. 540. 
a valorização e a fluidez dos bens $;^{37}$ a economia no pagamento de impostos; a possibilidade de maior autonomia do autor da herança; a celeridade da sucessão; a prevenção de litígios futuros; e o evitamento da dilapidação do patrimônio.

Entre as vantagens de se fazer o planejamento sucessório, um fator se destaca entre os principais: o de se pagar menos impostos. Com a organização fiscal e tributária, pode-se economizar dentro dos limites legais impostos pelo ordenamento.

\section{IMPORTÂNCIA DA DECISÃO DA INCONSTITUCIONALIDADE DO ART. 1.790 CC PELO STF NOS PRESSUPOSTOS DO PLANEJAMENTO SUCESSÓRIO}

Em 10 de maio de 2017 o Supremo Tribunal Federal finalizou o julgamento sobre a inconstitucionalidade do art. 1.790 do Código Civil. Dois processos foram julgados em definitivo: RE's 646.721 e 678.694. O primeiro deles foi o recurso extraordinário 878.694/MG que teve como relator o Ministro Luís Roberto Barroso. Tal julgamento teve início em agosto de 2016, já havendo desde então sete votos pela inconstitucionalidade da norma, na linha do proposto pela relatoria. ${ }^{38}$ Dessa forma, em maio de 2017 foram retomados os julgamentos das duas demandas. Para começar, o Ministro Marco Aurélio afirmou não haver razão para a distinção entre a união estável homoafetiva e a união estável heteroafetiva, na linha do que fora decidido pela Corte quando do julgamento da ADPF 132/RJ, em 2011. O placar do julgamento da RE 646.721 foi de 8 votos a 2, ausente o Ministro Dias Tofolli ${ }^{39}$ Quanto ao processo original, que deu início ao julgamento da questão

37 "A multiplicidade e diversidade de bens tornam mais possível o conflito entre os herdeiros e, pior, tornam mais difícil a solução". (MAMEDE, Gladston; MAMEDE, Eduarda Cotta. Planejamento sucessório: introdução à arquitetura estratégica - patrimonial e empresarial - com vistas à sucessão causa mortis. São Paulo: Atlas, 2015, p. 3).

38 Votaram nesse sentido os ministros Luiz Edson Fachin, Teori Zavascki, Rosa Weber, Luiz Fux, Celso de Mello e Cármen Lúcia, além do próprio ministro Barroso. Após pedido de vistas do ministro Dias Toffoli, o processo retomou seu destino neste ano de 2017, tendo esse último julgador concluído pela constitucionalidade da norma, pois haveria justificativa constitucional para o tratamento diferenciado entre o casamento e a união estável (voto prolatado no último dia 30 de março). O ministro Marco Aurélio pediu novas vistas, unindo também o julgamento do recurso extraordinário 646.721/RS, que tratava da sucessão de companheiro homoafetivo, do qual era relator, justamente o segundo processo.

39 Informativo n. 864 da Corte, "o Supremo Tribunal Federal (STF) afirmou que a Constituição prevê diferentes modalidades de família, além da que resulta do casamento. Entre essas modalidades, está a que deriva das uniōes estáveis, seja a convencional, seja a homoafetiva. Frisou que, após a vigência da Constituição de 1988, duas leis ordinárias equipararam os regimes jurídicos sucessórios do casamento e da união estável (Lei 8.971/1994 e Lei 9.278/1996). 
(RE 878.694/MG), o placar foi de 8 a $3^{40}$ pela inconstitucionalidade completa do art. 1.790 do Código Civil.

Cabe destacar que a tese final foi a de que "no sistema constitucional vigente, é inconstitucional a diferenciação de regimes sucessórios entre cônjuges e companheiros, devendo ser aplicado, em ambos os casos, o regime estabelecido no artigo 1.829 do Código Civil". O acórdão teve por base a finalidade de preservar a segurança jurídica, e deve ser aplicado apenas nos inventários judiciais em que a sentença de partilha não tenha transitado em julgado e nas partilhas extrajudiciais em que ainda não haja escritura pública.

Com o fim do julgamento do STF a principal vantagem é a de resolver a grande instabilidade jurídica sucessória verificada no Brasil desde a vigência do Código Civil de 2002, colocando fim a debates sobre a inconstitucionalidade ou não do art. 1.790 do Código Civil. Entretanto, ainda há vários questionamentos, tais como: como ficam os processos de inventário em curso? E os novos processos? Como devem ser elaboradas as escrituras públicas de inventários pendentes em Tabelionatos de Notas de todo o país? O companheiro passa a ser herdeiro necessário? A equiparação entre a união estável e o casamento é para todos os fins sucessórios? ${ }^{41}$

O Código Civil, no entanto, desequiparou, para fins de sucessão, o casamento e as uniōes estáveis. Dessa forma, promoveu retrocesso e hierarquização entre as famílias, o que não é admitido pela Constituição, que trata todas as famílias com o mesmo grau de valia, respeito e consideração. $\mathrm{O}$ art. 1.790 do mencionado código é inconstitucional, porque viola os princípios constitucionais da igualdade, da dignidade da pessoa humana, da proporcionalidade na modalidade de proibição à proteção deficiente e da vedação ao retrocesso". Disponível http://www. stf.jus.br/arquivo/informativo/documento/informativo864.htm. Acesso em:15 mar. 2018

40 Informativo 864 do STF, "o Supremo Tribunal Federal afirmou que a Constituição contempla diferentes formas de família, além da que resulta do casamento. Nesse rol incluem-se as famílias formadas mediante união estável. Portanto, não é legítimo desequiparar, para fins sucessórios, os cônjuges e os companheiros, isto é, a família formada por casamento e a constituída por união estável. Tal hierarquização entre entidades familiares mostra-se incompatível com a Constituição. O art. 1.790 do Código Civil de 2002, ao revogar as leis 8.971/1994 e 9.278/1996 e discriminar a companheira (ou companheiro), dando-lhe direitos sucessórios inferiores aos conferidos à esposa (ou ao marido), entra em contraste com os princípios da igualdade, da dignidade da pessoa humana, da proporcionalidade na modalidade de proibição à proteção deficiente e da vedação ao retrocesso". Disponível em http://www.stf.jus.br/arquivo/informativo/documento/informativo864.htm. Acesso em: 15 mar. 2018

41 TARTUCE, Flavio. STF encerra o julgamento sobre a inconstitucionalidade do art. 1.790 do Código Civil. E agora? Disponível em http://www.migalhas.com.br/FamiliaeSucessoes/104, MI259678,31047-STF+encerra+o+julgamento+sobre+a+inconstitucionalidade+do+art+179 0+do. Acesso em: 15 mar. 2018 
No recorte do tema do artigo, o planejamento sucessório, vale ressaltar que em seus pressupostos está a qualificação do autor da herança. Nesse caso deve-se definir se o companheiro é herdeiro necessário. Todavia, lendo os votos que prevaleceram, em especial o do Relator Luiz Roberto Barroso, o entendimento é que sim, o companheiro é herdeiro necessário. Cabe destacar que somente três ministros trataram do assunto diretamente. Foram eles:

\section{Voto do Ministro Luiz Roberto Barroso:}

Se é verdade que o CC/2002 criou uma involução inconstitucional em seu art. $1.790 \mathrm{em}$ relação ao companheiro, é igualmente certo que representou razoável progresso no que concerne ao regramento sucessório estabelecido no art. 1.829 para o cônjuge. No citado artigo 1.829, reforça-se a proteção estatal aos parceiros remanescentes do falecido, tanto pela sua elevação à condição de herdeiro necessário, como pelos critérios de repartição da herança mais protetivos em comparação com a legislação até então existente. ${ }^{42}$

\section{Voto do Ministro Edson Fachin:}

(viii) se a informalidade da constituição da relação que exige comunhão de vida para ser família, pudesse justificar direitos diferentes ou em menor extensão, também restaria afastada a incidência de regime de comunhão de bens, quanto aos efeitos inter vivos. $\mathrm{Na}$ sucessão, a liberdade patrimonial dos conviventes já é assegurada com o não reconhecimento do companheiro como herdeiro necessário, podendo-se afastar os efeitos sucessórios por testamento. Prestigiar a maior liberdade na conjugalidade informal não é atribuir, a priori, menos direitos ou diretos diferentes do casamento, mas, sim, oferecer a possibilidade de, voluntariamente, excluir os efeitos sucessórios. ${ }^{43}$

\section{Voto do Ministro Dias Toffoli:}

Vê-se, pela leitura dos textos, que, com o Código Civil de 2002, o cônjuge passou a concorrer com descendentes e, na falta desses, com ascendentes do autor da herança, se houver, e, quando é chamado à sucessão em concurso com descendentes, o cônjuge herda um quinhão da parte que não lhe cabe por força do regime de bens, mas sempre como herdeiro necessário, ao lado dos descendentes e ascendentes (cf. arts. 1.829, incisos I e II e 1.845 , do CC). ${ }^{44}$

Como se pode observar, a decisão sobre a inconstitucionalidade do art. 1.790 do Código Civil, ainda, não respondeu a tantos questionamentos. Pacificou um entendimento, entretanto, vários pontos precisam ser respondidos. Corrente encabeçada

42 Disponível http://portal.stf.jus.br/processos/detalhe.asp?incidente=4744004. Acesso em: 15 mar. 2018 file://C:/Users/User/Downloads/texto_313622639.pdf

43 Disponível http://portal.stf.jus.br/processos/detalhe.asp?incidente=4744004. Acesso em: 15 mar. 2018 file:///C:/Users/User/Downloads/texto_313622639.pdf

44 Disponível http://portal.stf.jus.br/processos/detalhe.asp?incidente=4744004. Acesso em: 15 mar. 2018 file://C:/Users/User/Downloads/texto_313622639.pdf 
por Anderson Schreiber e outros, defende a necessidade de haver equiparação somente para os fins de normas de solidariedade, caso das regras sucessórias, de alimentos e de regime de bens. Em relação às normas de formalidade, como as relativas à existência formal da união estável e do casamento, aos requisitos para a ação de alteração do regime de bens do casamento (art. 1.639, $\$ 2^{\circ}$ do CC e art. 734 do $\mathrm{CPC}$ ) e às exigências de outorga conjugal, a equiparação não deve ser total..$^{45}$

Segundo Gustavo Tepedino, a decisão do Supremo Tribunal Federal sobre a inconstitucionalidade do art. 1.790 do Código Civil apresenta, preliminarmente, duas reflexōes: a primeira de ordem técnica, pela ausência de discussão sobre a legitimidade do art. 1.845 do CC se aplicaria também ao companheiro e, a segunda, de ordem mais complexa, trataria da solidariedade familiar e como lidar frente às diversas formas de entidades familiares que compóem a sociedade contemporânea. ${ }^{46}$ Afirma, ainda, o autor

Diante de tamanha diversidade, para que o sistema se compatibilize com a legalidade constitucional, sem banalizar a elevada proteção conferida às famílias, o princípio da solidariedade, com a responsabilidade que lhe é ínsita, deve ser acompanhado da autonomia que alicerça a dignidade humana. Vale dizer, há que se fomentar a responsabilidade pelas escolhas de vida e a autonomia dos conviventes, inclusive no que tange à liberdade testamentária. ${ }^{47}$

Pode-se entender que é profunda a discursão do tema solidariedade e autonomia na sucessão entre cônjuges e companheiros. Na verdade, a temática "solidariedade e autonomia" permeia todo o direito sucessório brasileiro.

\section{CONSIDERAÇÕES FINAIS}

Ao longo deste artigo, demonstrou-se, a importância e as vantagens do planejamento sucessório na atualidade brasileira, tendo em vista a necessidade de se rever

45 TARTUCE, Flavio. STF encerra o julgamento sobre a inconstitucionalidade do art. 1.790 do Código Civil. E agora? Disponível em http://www.migalhas.com.br/FamiliaeSucessoes/104, MI259678,31047-STF+encerra+o+julgamento+sobre+a+inconstitucionalidade+do+art+179 0+do. Acesso em: 15 mar. 2018.

46 TEPEDINO, Gustavo. Solidariedade e autonomia na sucessão entre cônjuges e companheiros". Revista Brasileira de Direito Civil. - RBDCivil. Editorial. Belo Horizonte. Vol. 14. P. 1113. out/dez. 2017. Disponível em <https://rbdcivil.ibdcivil.org.br/rbdc/article/view/163/158>. Acesso em: 15 mar. 2018.

47 TEPEDINO, Gustavo. Solidariedade e autonomia na sucessão entre cônjuges e companheiros". Revista Brasileira de Direito Civil. - RBDCivil. Editorial. Belo Horizonte. Vol. 14. P. 1113. out/dez. 2017. Disponível em <https://rbdcivil.ibdcivil.org.br/rbdc/article/view/163/158>. Acesso em: 15 mar. 2018. 
todo o direito das sucessões, devido a seu descompasso com a sociedade. Contudo, antes que ocorra a desejada alteração legislativa, deve-se explorar o sistema disponível do ordenamento jurídico na legalidade constitucional. Por isso é necessário se fazer o planejamento sucessório para que ocorra a funcionalização do direito das sucessões conforme princípios da autonomia e da solidariedade familiar.

Em relação à inconstitucionalidade do art. 1.790 do Código Civil, como se pode perceber, os julgamentos do Supremo Tribunal Federal resolveram aspecto importante até o momento. Entretanto, o acórdão foi publicado em 06/02/2018 e foram opostos embargos de declaração em 26/02/2018. Assim, o tema ainda carece de respostas. Apesar de ser possível sinalizar alguns entendimentos doutrinários, estes não resolvem todos os problemas da temática sucessória.

\section{REFERÊNCIAS}

AMARAL, Francisco. Direito civil: introdução. 6. ed. ver. atual. e aum. Rio de Janeiro: Renovar, 2006.

BAUMAN, Zygmunt. Modernidade líquida. Tradução de Plínio Dentzien. Rio de Janeiro: Jorge Zahar, 2001.

BAUMAN, Zygmunt. Vida líquida. Tradução de Carlos Alberto Medeiros. Rio de Janeiro: Jorge Zahar, 2007.

CAPELO DE SOUSA, Rabindranath. Liçôes de direito das sucessöes, vol. 1. 3. ed., 2. Reimpressão. Coimbra. Coimbra editora, 1997.

CRUZ, Elisa; AZEVEDO, Lilibeth. Planejamento sucessório. In: TEPEDINO, Gustavo; FACHIN, Luiz Edson (Org.). Diálogos sobre direito civil, vol. III. Rio de Janeiro: Renovar, 2012, p. 537-562.

GALVAO TELLES, Inocêncio. Apontamentos para a história do direito das sucessōes português. Separata da Revista da Faculdade de Direito da Universidade de Lisboa. Lisboa, v. XV, 1963.

GAYA, Karyna Saraiva Leão. Planejamento sucessório: uma saudável preocupação com o futuro. Revista Sintese: Direito de Família. Porto Alegre: Síntese, ano XIII, n. 70, fev./mar. 2012, p. 124-125.

GIDDENS, Anthony. A vida em uma sociedade pós-tradicional. In: GIDDENS, Anthony; LASH, Scott; BECK, Ulrich (Org.). Modernização reflexiva: política, tradição, estética na ordem social moderna. 2. ed. Tradução de Magda Lopes. São Paulo: Unesp, 2012, p. 89-166.

GUEDES, Gisela Sampaio da Cruz; TERRA, Aline de Miranda Valverde. Alienação fiduciária em garantia de bens imóveis: possíveis soluçôes para as deficiências e insuficiências da disciplina legal. Civilistica.com. Rio de Janeiro, a. 4, n. 1, 2015. Disponível em: $<$ http://civilistica.com/alienacao-fiduciaria-em-garantia-de-bens-imoveis/>. Acesso em: 6 jan. 2016. 
HIRONAKA, Giselda Maria Fernandes Novaes. Planejar é preciso: planejamento sucessório para as novas famílias. Entrevista. Revista IBDFAM. Belo Horizonte: Instituto Brasileiro de Direito de Família, 10 ed., abr. 2014, p. 5-7.

MADALENO, Rolf. Planejamento sucessório. Revista IBDFam: Famílias e Sucessões. Belo Horizonte: IBDFAM, v. 1, jan./fev. 2014, p. 11-33.

MAMEDE, Gladston; MAMEDE, Eduarda Cotta. Planejamento sucessório: introdução à arquitetura estratégica - patrimonial e empresarial - com vistas à sucessão causa mortis. São Paulo: Atlas, 2015.

MORAES, Maria Celina Bodin de. A família democrática. In: MORAES, Maria Celina Bodin de. Na medida da pessoa humana - estudos de direito civil-constitucional. Rio de Janeiro: Renovar, 2010, p. 207-234.

NEVARES, Ana Luiza Maia. A função promocional do testamento. Revista Brasileira de Direito das Famílias e Sucessões. Abr-Maio. vol. 9. Porto Alegre: Magister, 2009.

OLIVA, Milena Donato. Do negócio fiduciário à fidúcia. São Paulo: Atlas, 2014.

OLIVEIRA, Euclides de. Planejamento sucessório: regime de bens e seu reflexo na transmissão da herança. Federação das Indústrias do Estado de São Paulo - FIESP. Disponível em: <http://www.fiesp.com.br/irs/conjur/pdf/transparencias_reuniao_conjur_25_10_10_-_euclides_benedito_de_oliveira_planej_sucess_palest_conjur.pdf $>$. Acesso em: 14 jul. 2011.

PINTENS, Walter. Need and opportunity of convergence in European succession laws. In: ANDERSON, Mirian; ARROYO I AMAYUELAS, Esther (Ed.). The law of succession: testamentary freedom. European perspectives. Amsterdam: European Studies in Private Law, 2011, p. 3-24.

REALE, Miguel. Liçôes preliminares de direito. 25. ed. São Paulo: Saraiva, 2000.

REBOLLEDO VARELA, Ángel Luis. La actualización del derecho sucesorio espanõl ante los cambios sociológicos y jurídicos de la familia: conclusiones de una investigación. In: REBOLLEDO VARELA, Ángel Luis (Coord.). La familia en el derecho de sucesiones: cuestiones actuales y perspectivas de futuro. Madrid: Dykinson, 2010, p. 23-42.

ROUDINESCO, Elizabeth. A família em desordem. Tradução de André Telles. Rio de Janeiro: Jorge Zahar, 2003.

SANTOS, Boaventura de Sousa. Pela mão de Alice: o social e o político na pós-modernidade. 8. ed. São Paulo: Cortez, 2001.

SUPREMO TRIBUNAL FEDERAL. Disponível http://portal.stf.jus.br/processos/detalhe.asp? incidente $=4744004$. Acesso em: 15 mar. 2018.

SUPREMO TRIBUNAL FEDERAL. Disponível http://www.stf.jus.br/arquivo/informativo/documento/informativo864.htm. Acesso em: 15 mar. 2018. 
TARTUCE, Flavio. STF encerra o julgamento sobre a inconstitucionalidade do art. 1.790 do Código Civil. E agora? Disponível em http://www.migalhas.com.br/FamiliaeSucessoes/104,MI259678,31047-STF+encerra+o+julgamento+sobre+a+inconstitucionalidade+do+art+1790+do. Acesso em: 15 mar. 2018.

TEIXEIRA, Daniele. Planejamento Sucessório: pressupostos e limites. 2. reimpr. Belo Horizonte: Fórum, 2018.

TEPEDINO, Gustavo. A disciplina civil-constitucional das relaçôes familiares. In: TEPEDINO, Gustavo. Temas de direito civil. 3. ed. rev. atual. Rio de Janeiro: Renovar, 2004, p. 395-416.

TEPEDINO, Gustavo. Livro (eletrônico) e o perfil funcional na experiência brasileira. In: VICENTE, Dário Moreira; VIEIRA, José Alberto Coelho; CASIMIRO, Sofia de Vasconcelos; SILVA, Ana Maria Pereira da (Org.). Estudos de direito intelectual em homenagem ao Prof. Doutor José de Oliveira Ascensão. 1. ed. Coimbra: Almedina, 2015, p. 269-287.

TEPEDINO, Gustavo. Regime jurídico dos bens no Código Civil. In: Venosa, Sílvio de Salvo; Gagliardi, Rafael Villar; Nasser, Paulo Magalhães (Coord.). 10 anos do Código Civil: desafios e perspectivas. São Paulo: Atlas, 2012, p. 47-78.

TEPEDINO, Gustavo. Solidariedade e autonomia na sucessão entre cônjuges e companheiros". Revista Brasileira de Direito Civil - RBDCivil. Editorial. Belo Horizonte. Vol. 14. P. 11-13. out/dez. 2017. Disponível em <https://rbdcivil.ibdcivil.org.br/rbdc/article/ view/163/158>. Acesso em: 15 mar. 2018.

TEPEDINO, Gustavo; BARBOZA; Heloisa Helena; MORAES, Maria Celina Bodin de. Código Civil interpretado conforme a Constituição da República I. Rio de Janeiro: Renovar, 2004.

VIEIRA, Liszt. Cidadania e globalização. 5. ed. Rio de Janeiro: Record, 2001. 
